\title{
Flora Tristán: su papel en la constitución del socialismo y de la clase obrera francesa
}

\author{
Hernán M. Díaz
}

UBA

\section{Introducción}

El solo hecho de que una mujer esté presente entre los fundadores del socialismo, antes de la aparición fulgurante de Marx y Engels y antes de la Primera Internacional, ese solo hecho, repetimos, debiera llamar la atención acerca de la estrecha relación que une al socialismo con una reivindicación de un nuevo estatus de la mujer con respecto a la sociedad masculina que la oprime. Reciprocamente, coloca al socialismo muy por encima de todas las doctrinas politicas liberales, que enarbolaban consignas de igualdad y libertad, pero sólo a regañadientes, y tras penosas luchas, le fueron concediendo a la mujer los derechos que le correspondian. Si alguna mujer ocupó en su época un lugar preminente dentro del liberalismo, lo hizo en el ámbito peyorativamente femenino de la "literatura": desde Madame de Staël hasta George Sand, en Francia, o desde Mary Shelley hasta George Elliot, en Inglaterra.

Flora Tristán no solamente fue una mujer que escribió y creó ideas nuevas en el naciente socialismo francés de la década de 1840, sino que además, y fundamentalmente, condensó en su pensamiento las mejores concepciones que habian elaborado sus antecesores, le acercó a los obreros franceses la experiencia más importante de organización proletaria que era el cartismo inglés, planteó la necesidad de una constitución política de la clase obrera y desplegó un enorme esfuerzo militante por poner en práctica esta idea en una veintena de ciudades de Francia. Flora Tristán no fue una socialista revolucionaria. Al contrario, su idea de constitución de la clase obrera la entendía dentro de una política pacifista y reformista, y afirmó reiteradas veces (sobre todo en su libro La unión obrera) que su intención era "impedir las revoluciones, porque las revoluciones son contrarias a la libertad y a los verdaderos intereses del pueblo" (Tristán, 1993: 178). Pero 
podemos afirmar que hizo mucho más por poner en pie el movimiento obrero francés e internacional que aquellos que buscaban despertar al pueblo "desde afuera", con insurrecciones elaboradas en un laboratorio clandestino.

El socialismo maduro de Marx y Engels tiene, desde el punto de vista político, dos origenes diferentes: una fuente son los grupos insurreccionalistas, ateos y comunistas, que parten de Graco Babeuf y se continúan con Filippo Buonarroti y, en Francia, con Auguste Blanqui. Se trata siempre de pequeños grupos conspirativos, alejados de las luchas concretas de la clase obrera de carne y hueso, con un basamento ideológico muy pobre (la acción era todo y la teoría era considerada diletantismo) y poco diferenciados del revolucionarismo democrático pequeño burgués. La otra fuente son los grupos reformistas que evolucionaron desde un intento de reforma de la sociedad capitalista hasta la elaboración de una vasta concepción político-histórica que justificaba la emancipación obrera y popular a través del socialismo. Se trata de las grandes elaboraciones, contradictorias y en permanente evolución, de Saint-Simon, Fourier, Owen y sus múltiples seguidores. En este segmento debemos incluir a Flora Tristán, quien transitó las diferentes vertientes del socialismo reformista cuando éste ya se encontraba en decadencia y en dispersión. La síntesis de esas dos fuentes fue realizada por Marx y Engels, tomando el impulso revolucionario del primer grupo pero recuperando los aspectos críticos y analíticos más significativos de los ideólogos reformistas.

En ese marco incluiremos el análisis de algunas ideas específicas de Flora Tristán. No podemos obviar al principio referir algunos breves apuntes biográficos, ya que su obra está intimamente ligada a las circunstancias que le tocó vivir. Luego nos abocaremos a un análisis de sus propuestas y qué significado le asignamos en la historia del socialismo, del feminismo y en la constitución del movimiento obrero francés. Pero al analizar las concepciones de Flora Tristán, tanto sobre el socialismo obrero como sobre la emancipación de la mujer, nos remontaremos a los antecedentes que subyacen a sus ideas. Nuestra preocupación será poder identificar a Flora como el punto en una trama, que se está desarrollando desde dos décadas atrás y que tendrá su eclosión en la revolución de 1848 .

\section{Acercamiento al socialismo y al feminismo}

Flora Tristán nació en París en 1803, hija de Thérèse Laisney y de Mariano Tristán, general del ejército español nacido en Perú, hermano a su vez de Pío Tristán. Este último combatió a las fuerzas independentistas de Belgrano y Güemes, en el norte argentino. Mariano Tris- 
tán, paradójicamente, fue amigo de Simón Bolívar, quien frecuentaba a la familia en París hasta que aquél murió tempranamente, cuando Flora tenía cinco años, hecho que dejó a su mujer y a su huérfana en la ruina.

Ya en la adolescencia, Flora aprendió dibujo y entró a trabajar en un taller de grabado, y al poco tiempo se casó con su patrón, André Chazal, con quien tuvo tres hijos: un varón que vivió pocos años, Ernest y Aline. Pero Chazal resultó ser alcohólico, golpeador y jugador, y Flora, antes del nacimiento de su tercera hija, se separa, lo cual la lleva a una larga situación de constante acoso judicial y personal por parte de su marido, que culmina en un intento de homicidio: Chazal le dispara a su ex mujer en plena calle, hiriéndola de gravedad. Flora se recupera y su marido es condenado a veinte años de trabajos forzados. Recién entonces se le concede la tenencia de sus hijos.

Los largos años de disputa judicial y personal con André Chazal (desde 1825 , cuando se divorcia, hasta el atentado a su vida en 1838) fueron, para Flora, años de aprendizaje. Viajó reiteradas veces a Inglaterra, Suiza e Italia, como dama de compañía o institutriz; realizó un viaje a Perú de dos años, intentando infructuosamente que su tío la reconociera como heredera, y plasmó esta aventura en un libro, Peregrinaciones de una paria. Un tema recurrente del libro eran los infortunios que padece una mujer divorciada en una sociedad prejuiciosa y conservadora. Esta publicación le dio cierto nombre literario en París, que ella aprovechó para publicar una novela, algunos folletos (uno de ellos proponiendo una ley de divorcio) y frecuentar los salones de moda, en especial los de ambiente republicano y democrático. Pero estos años significaron, sobre todo, el encuentro paulatino con dos corrientes ideológicas donde Flora dejará una huella personal: el socialismo y el feminismo. Estando convaleciente del parto de su tercera hija en 1825, lee Vindicación de los derechos de la mujer, de Mary Wollstonecraft, y Del sistema industrial, del Conde de Saint-Simon.

En los años siguientes, Flora estuvo atenta al desarrollo de estos movimientos y tuvo la posibilidad de leer y conocer a sus principales dirigentes, tanto de Francia como de Inglaterra. En 1829 conoció a Prosper Enfantin, "padre" de la religión sansimoniana después de la muerte del maestro. Visitó también a Charles Fourier, teórico de la otra gran corriente de pensamiento socialista de la época, antes de su muerte en 1837. Fue muy amiga de su sucesor, Victor Considerant, más político y mejor organizador de esa corriente que Fourier. Considerant publicó en su periódico, La Phalange, un extracto de la propuesta de unión obrera de Flora Tristán. También podemos señalar que Flora conoció a las pocas feministas que abogaban por la emancipación de la mujer, como Jeanne Deroin, Pauline Roland y Hortense Allart. Por último, fue 
amiga de Agricole Perdiguier, dirigente del compagnonnage, ${ }^{1}$ que fue la base sobre la que trabajó Flora para su unión obrera.

Sus contactos no se limitaron a Francia. En 1840 entrevistó a Robert Owen en una visita que éste hizo a Paris. Trabajando en Inglaterra de dama de compañia, fue amiga del matrimonio de William Thompson y Anna Wheeler, economistas y fourieristas, quienes publicaron en 1826 un famoso opúsculo feminista: "Llamado a la mitad de la raza humana, mujeres, contra las pretensiones de la otra mitad, hombres, de mantenerlas en la esclavitud politica, civil y doméstica". Por último, en un viaje a Londres en 1839 conoció al cartismo, organización amplia de la clase obrera inglesa, y participó en una reunión de su comité central. También asistió a una sesión del parlamento, donde escuchó las palabras de Daniel O'Connell en defensa del pueblo irlandés. Esta última experiencia la relata en Paseo por Londres, publicado en Francia en 1840. En definitiva, Flora se nutrió con lo mejor del pensamiento socialista y feminista de su época y desde comienzos de la década de 1840 se consideró socialista, sin adscribir específicamente a ninguna de las diversas doctrinas que habia conocido.

A partir de esa definición política, Flora Tristán estrecha sus vínculos con los círculos obreristas de todo tipo, en especial con Victor Considerant, líder del fourierismo, y con Pauline Roland, vinculada al feminismo sansimoniano. La misma publicación de Paseo por Londres es concebida como un acto de proselitismo. En ese libro se traza un panorama de la situación económica, social y política de Inglaterra y hay un largo capítulo relatando la presencia de la autora en una reunión del comité central del cartismo. Por otra parte, hay una descripción de la terrible situación económica de la clase obrera inglesa, que anticipa tanto la Situación de la clase obrera de Inglaterra de Engels (de 1844) como las pinturas homólogas de Marx en El capital (1867). De este libro se vendieron tres ediciones en pocos años.

En un intento por insertarse de manera definitiva en el ambiente

1. El compagnonnage era una especie de organización de artesanos para el aprendizaje de los oficios: cada obrero, para especializarse en una disciplina, viajaba por distintas ciudades de Francia, donde era hospedado por otros miembros de la hermandad para aprender los secretos de su tarea. Una vez cumplido este cursus honorum, ya podía considerarse oficial y hasta abrir su propio taller. El compagnonnage no fue una organización estable a nivel nacional, sino que en rigor se trataba de una red de vínculos interurbanos de obreros del mismo oficio. Esta red, hacia mediados del siglo XIX, estaba ya en decadencia y los diferentes grupos que lo integraban no podian superar sus rivalidades, ideológicas y económicas, pues cada uno representaba a un sector artesanal diferente. El compagnonnage tenía vínculos con la organización de los masones, con quienes Flora también estaba relacionada. 
literario de la época, Flora abre un salón en su casa los domingos, donde recibirá tanto a escritores como a ideólogos y obreros de todo tipo. Allí mismo concurrió Arnold Ruge, quien planificaba publicar junto a Karl Marx sus Anales franco-alemanes. El proyecto anunciado en el título era combinar la filosofia alemana con el socialismo francés, pero los intentos de Ruge por asociar alguna pluma francesa fracasaron ante la negativa de todos los contactos en Francia por participar en la publicación. Flora fue una de ellas, seguramente poco dispuesta a asociarse a un grupo ateo y revolucionario. Aun así, Marx y Engels, en La sagrada familia, defendieron dos años después sus planteos, en un capítulo de discusión con Edgar Bauer. ${ }^{2}$

\section{La constitución de la clase obrera}

En estos años, Flora Tristán va consolidando la idea de que la clase obrera francesa debe "constituirse", así como se ha constituido la clase obrera inglesa. En La unión obrera, libro que publica en 1843, Flora propone que los trabajadores se organicen en un solo cuerpo, en una especie de institución única, mezcla de partido y de sindicato, que le permita defender su estándar de vida y poder tener una voz en la política francesa. En esta gran unidad obrera, los trabajadores y las trabajadoras aportarían cada uno 2 francos al año con un doble objetivo: el primero, construir "palacios obreros", donde se pueda cuidar de los enfermos y los ancianos e instruir a los niños en oficios útiles para su vida adulta; el segundo, poder rentar a un hombre "de corazón y de talento" para que defienda en el parlamento las reivindicaciones de la clase obrera.

La idea de una autoorganización integral de la clase trabajadora es una traducción que realiza Flora de lo que observa en la clase obrera inglesa, donde los cartistas han logrado unir detrás suyo al conjunto de sindicatos y sociedades obreras existentes. Inglaterra es el país donde la revolución industrial se ha desarrollado más y, en consecuencia, la clase trabajadora también se ha alejado más de sus orígenes campesinos y artesanales. Pero también es verdad que Francia es el país del desarrollo ideológico por excelencia: aquello que los ingleses han hecho de manera práctica y empírica, los franceses lo sentencian por la vía de sus planteos teóricos. Con Marx podríamos agregar que los alemanes lo consuman de manera filosófica, y ya tenemos una realidad "europea" propia de los prolegómenos de la revolución de 1848.

Las funciones que cumplirian los palacios obreros que propone la

2. El prólogo de esta obra de Marx y Engels está fechado en septiembre de 1844, dos meses antes de la muerte de Flora, y el libro se publicó al año siguiente. 
pensadora francesa prefiguran, en cierta manera, lo que más tarde serán las organizaciones mutuales, las jubilaciones y la educación pública. Con ellos, la organización de los trabajadores cubría tres aspectos en los que el Estado liberal abandonaba a su suerte a la familia obrera y así, indirectamente, se buscaba defender una parte del salario obrero. Es inevitable pensar que, con esta propuesta, es el propio proletariado el que se hace cargo de los gastos que ocasionarian la salud, la educación y el salario tras el retiro de la vida laboral. Su virtud radica en que la propuesta es realizada como parte de la conformación de un movimiento político de la clase obrera y, por ello mismo, se empieza a considerar la posibilidad de una toma de posición al respecto.

La idea de una unión de los trabajadores franceses, y eventualmente de todos los obreros de Europa, como plantea Flora, es una novedad radical en el ambiente del movimiento socialista francés. Y aunque la idea fuera tomada de la organización del cartismo inglés, también es una novedad para el proletariado europeo, ya que la unión de los trabajadores ingleses se habia dado de hecho, pero no como una conclusión teórica necesaria para la emancipación del proletariado.

El proletariado, en las diferentes teorias que van a conformar el socialismo, aparece primero como objeto, y se va transformando en sujeto muy paulatinamente. Es Saint-Simon, en la década de 1820, el primero que toma la mejora de la situación del proletariado como el único objetivo al que deben concurrir los esfuerzos del Estado: "Toda la sociedad debe trabajar en la mejora de la existencia moral y física de la clase más pobre" (2004: 67). Esta clase, "la más numerosa y más pobre", según su reiterada definición, es objeto de una política, nunca sujeto. Son los gobiernos primero, el propio movimiento sansimoniano después, los que deben desarrollar una política para erradicar tanto la pobreza como las guerras. Pero ni en las obras de Saint-Simon ni en las de sus discípulos inmediatos, Prosper Enfantin o Saint-Amand Bazard, se encuentra una preocupación por que los obreros se organicen separadamente y detrás de fines propios, en función de su emancipación.

Pero la historia no es lineal: el mero hecho de que se haya tomado como objeto al proletariado, hace que los trabajadores, después de la revolución de 1830, se vuelquen masivamente a las filas sansimonianas, porque observan que el nuevo Estado liberal gobierna sólo para los burgueses y desprecia toda preocupación por la vida de los proletarios. Los sansimonianos crean entonces comités de trabajadores (llamados "grado de los industriales" o "de los obreros") en varios barrios de París, y reciben el apoyo entusiasta de cientos de obreros y obreras que ven en la "religión sansimoniana" un mensaje de redención y de superación de su situación (Picon, 2002: 112-127; Rancière, 2010: 181-211; Démier, 2004). El sansimonismo estalla en 1832 por disensiones internas que 
no detallaremos ahora, pero deja un legado: ha inculcado en cientos de trabajadores la idea de que su emancipación es posible y que deben tomar ellos mismos la iniciativa para conquistarla. El obrero seguía siendo objeto en el terreno de las ideas, pero ahora ya participaba en cierta manera como sujeto. Todavía no se visualizaba la necesidad de una organización de clase, pero la clase ya aparecía organizada dentro de una doctrina que la tenía como protagonista.

Del sansimonismo se desprenden varias corrientes teóricas que llevan la doctrina por andariveles no previstos por los iniciadores. Philippe Buchez busca desarrollar un obrerismo católico y, a instancias suyas, se crea en 1840 la revista L'Atelier, escrita exclusivamente por obreros manuales. Esta revista profesa una doctrina pacifista, reformista, y subordina la emancipación del trabajador a la conquista previa del sufragio universal, consigna que levantan ahora los demócratas republicanos. En cierta manera, para L'Atelier el obrero es ahora el centro de toda organización, pero con objetivos meramente defensivos: mutualismo, defensa de las condiciones de trabajo y de salario, etc. Desde el punto de vista teórico, empiezan a depender del auge de las ideas del liberalismo radical.

Otro sansimoniano, Louis Blanc, encuentra en la "organización del trabajo" la gran tarea de la época. En resumen, consiste en superar la desocupación y la miseria del trabajador a través de la propuesta de creación de fábricas estatales en cada rama de la producción para competir con la industria privada y forzar los precios a la baja. Su prédica tiene un éxito enorme, al punto de que cuando se produce más tarde la revolución de 1848, Blanc forma parte del gobierno provisional y los obreros, encabezados por banderas rojas, le reclaman al nuevo gobierno que cumpla con aquella consigna: la "organización del trabajo". Estamos nuevamente en presencia de una idea donde la clase obrera sólo está organizada en la medida en que el Estado lo permite, detrás de una institución económica controlada paritariamente.

Flora Tristán es la primera pensadora socialista que desarrolla la idea de que son los mismos obreros los que están llamados a protagonizar su liberación. "Hermanos, unámonos", consigna que Flora enarbola en su obra dirigiéndose a los trabajadores, ha sido considerada la anticipación de "Proletarios del mundo, uníos" (Marco, 1993), lema de la Asociación Internacional de Trabajadores. Su intención declarada es "constituir la clase obrera", y esto significa que la constitución del proletariado no es su instalación económica como oferente de trabajo libre, es decir una constitución como clase en sí, sino que se trata de una constitución política, consciente, con un destino propio y en lucha contra quienes la oprimen. Ya hemos sugerido que la lucha que plantea Flora Tristán es una lucha internacionalista (idea que proviene directamente de Saint- 
Simon). Así, afirma que la unión "no debe hacer ninguna distinción entre los obreros nacionales y los obreros y obreras pertenecientes a no importa qué nación de la tierra. Así, para todo individuo considerado extranjero, los beneficios de la Unión serán absolutamente los mismos que para los franceses" (Tristán, 1993: 137). También afirma que la unión obrera deberá extenderse a toda Francia y todas las ciudades europeas que quieran asociarse.

En el resumen con el que finaliza su libro La unión obrera, el primer punto expresa: "Constituir la clase obrera por medio de una unión compacta, sólida e indisoluble". A diferencia de lo que observamos hoy, en el siglo XXI, cuando la idea misma de "clase obrera" es cuestionada desde diversas ideologías, cuando se intenta disolver la existencia de los asalariados en un sinfin de pequeños grupos sin homogeneidad y sin proyecto, Flora Tristán defendia la necesidad de que el proletariado se constituya como clase para lograr su emancipación política y económica. La clase obrera no estaria constituida por el mero hecho de dejar de ser artesanos o campesinos (proceso que en Francia llevaría todo el siglo XIX), sino a partir de tener conciencia de su rol histórico y de buscar la emancipación por sus propios medios. Con Flora Tristán el trabajador pasa a ser el centro de la lucha política y, para ello, debe constituirse como clase en forma diferenciada del resto de las clases sociales: "Es necesario absolutamente que el pueblo sólo cuente consigo mismo, si él confia sus intereses a los burgueses estará perdido" (Tristán, 1973: 79).

Agregaremos algo más: discute la famosa definición de Saint-Simon de la clase obrera como "la clase más numerosa y más pobre". Para Flora, debe hablarse de "la clase más numerosa y más útil" (1993: 81), porque la pobreza, afirma, no es una cualidad, en cambio la utilidad es lo que verdaderamente muestra el rol social del proletariado. Aunque no lo desarrolla con una explicación marxista, está aquí prefigurando la idea de que la clase obrera es la clase revolucionaria por el papel que desempeña en la producción, y no por ser la clase más pobre, ya que otras clases (por ejemplo, el campesinado) pueden ser más pobres que la clase obrera en muchos países y momentos diferentes. La "utilidad" de Flora significa que el proletariado es el creador de toda la riqueza social, y que esa utilidad es la que lo pone en un papel central en el liderazgo del resto de clases explotadas por el capital.

Todavía la idea de "emancipación" (tanto de los trabajadores como de las mujeres) permanece en una nebulosa indiferenciada en el futuro y no se sabe cómo se conseguirá ni qué implicancias precisas puede llegar a tener, pero se ha dado el primer paso: concebir que la clase obrera debe constituirse como clase, separarse de las otras clases sociales, lograr una voz propia y tener presencia política en el ámbito de Francia y de 
Europa. Los tiempos estaban llamados para que el proletariado hiciera irrupción en la sociedad, Flora fue la primera en plantearlo.

\section{La gira por Francia}

La propuesta de Flora Tristán no fue un proyecto teórico ni esperó que el tiempo la consumara. A los 40 años, en 1843, empezó a relacionarse con diversos círculos proletarios y socialistas, publicó su libro La unión obrera (que tuvo varias ediciones en los años siguientes) y salió a realizar una gira por toda Francia para ganar adeptos para su causa. Recorrió una veintena de ciudades de su país, entre las que se destacaron las adhesiones logradas en Lyon, Marsella y Toulouse. Tuvo serios problemas con la policía, que le incautaba papeles, le prohibía reuniones o la invitaba a abandonar el pueblo, y muchas veces la prensa burguesa del lugar hacía comentarios ofensivos hacia su obra y, más generalmente, hacia su persona. Nunca faltaban el sarcasmo sexista y la mentira lisa y llana, y en Lyon un diario liberal la acusó de agente del gobierno. Por otra parte, en cada pueblo visitaba las librerias donde se podian vender sus libros: muchos los aceptaban, otros los rechazaban por "peligrosos". Un librero, en Bordeaux, le confiesa que ha vendido 30 ejemplares y no quiere más, porque su negocio se llena de gente "de blusa y gorrito", y eso no es de buen tono.

En general, a su llegada se vinculaba directamente con los circulos ya organizados del compagnonnage. Flora trataba de que se superaran las disensiones internas de este sector, pero la dificultad mayor consistía en que aquélla no era una organización política sino laboral. En sus reuniones estaba prohibido hablar de politica, y Flora debió elaborar distintas estrategias para transmitir su mensaje. El vínculo con el compagnonnage es otro hilo más que Flora recoge de la trama deshilachada del movimiento social francés. Toma la organización efectivamente existente del semiproletariado artesanal de Francia e intenta transformarla en una organización indiferenciada de trabajadores, con un objetivo de emancipación política. Tuvo la virtud de no buscar la organización en los círculos de estudiantes o literatos sensibles a lo social, como hicieron otros grupos socialistas, sino que se basó en la organización real que todavía tenía el trabajador de oficio, trabajador que se estaba transformando aceleradamente en un ser "libre" que ofrece su trabajo "libre" en el mercado.

De todas formas, Flora no se quedó en los círculos de artesanos: éstos eran los que mejor y más pronto la recibían, pero también estuvieron entre los más reacios a encarar un trabajo político. En cada pueblo intentaba contactar a obreros sin partido, a otros grupos socialistas e incluso se entrevistaba con burgueses y eclesiásticos: Flora 
insistía en que los trabajadores, para constituirse como clase, debian poder dialogar con todas las otras clases de la sociedad. Entre los más politizados, Flora se encontró con todos los grupos que actuaban en la Francia de la Monarquía de Julio: fourieristas, comunistas de Étienne Cabet, viejos sansimonianos, comunistas revolucionarios, y también con algunos republicanos, demócratas y radicales, cuyo único credo, según Flora, era tomar el fusil al primer llamado revolucionario y abogar por el sufragio universal.

La reacción más negativa la tuvo entre los fourieristas, a pesar de que ella era amiga de su máximo dirigente, Victor Considerant, y que éste le hubiera publicado un extracto de su obra en el periódico La Phalange. Pero el grueso del movimiento estaba conformado por burgueses, a la espera de que otros burgueses se unan al movimiento para poder financiar uno de los famosos falansterios rurales de Fourier. Tampoco se llevó bien con los comunistas de Cabet (llamados icarianos), a pesar de que tanto Flora como Cabet pregonan un socialismo pacífico y reformista. Pero los icarianos creen contar con un proyecto del mundo futuro mucho más acabado que el de Flora, quien sólo habla de una "emancipación" general de obreros y obreras, sin detenerse en la descripción detallada de la sociedad del porvenir. Entre los sansimonianos encuentra buenos partidarios, sobre todo porque tienen una similar sensibilidad por la emancipación de las mujeres. Aun así, la mayoría de éstos han quedado muy desmoralizados por el descrédito en el que cayó el sansimonismo después de la crisis de 1832, donde los principales dirigentes de París fueron ridiculizados públicamente, perseguidos y encarcelados. En cuanto a los comunistas revolucionarios, están más cerca de los radicales republicanos que de los socialistas en general: comparten con los radicales la pasión por las armas y la vacuidad teórica, pero desestiman la lucha por el sufragio y la reforma política.

Más allá de sus adscripciones políticas, Flora Tristán se entrevista con centenares de obreros. En cada ciudad logra organizar reuniones de 20,30 y hasta 100 obreros. Se queja constantemente del atraso cultural y político del proletariado (salvo de los obreros de Lyon, que son buenos lectores de temas sociales), pero insiste en explicar pacientemente la necesidad imperiosa de que los trabajadores y las trabajadoras se organicen unificadamente en forma nacional. Las reuniones se realizan en casas de obreros, en talleres, en locales de instituciones de diverso tipo. Algunas son prohibidas por la policía, pero en general se pueden desarrollar sin problema. En París se va a fundar un periódico de corta vida, L'Union, que seguirá desarrollando las ideas de Flora Tristán. En Lyon, Marsella y Toulouse se crean pequeños grupos de seguidores, siendo el de Marsella el más importante. Toda esta tarea queda en parte truncada por la temprana muerte de Flora, en noviembre de 1844, en la 
ciudad de Bordeaux, cuando todavía le quedaban varias ciudades por visitar. ${ }^{3}$ Su prédica será continuada por quienes la conocieron en vida, en particular por su seguidora más fiel, Eléonore Blanc, a quien Flora conoce en Lyon, y sobre todo por Pauline Roland, quien en medio de la revolución de 1848 organizará y dirigirá el sindicato de maestros.

Pero aunque su vida haya sido corta y sus pensamientos circularan en unos pocos libros, los conceptos quedaban planteados. Algunos dirigentes, grupos de obreros en diversas ciudades, retomarán esas ideas, que entroncarán provisoriamente en el mar de luchas que lleva a la revolución de 1848. Y cada concepto se va convirtiendo en un eslabón más de la cadena ideológica que va construyendo el socialismo y, a la vez, va constituyendo al movimiento obrero como tal.

\section{Feminismo y socialismo}

El segundo gran aspecto que debemos analizar entre las ideas de Flora Tristán es su feminismo socialista. Ya hemos dicho que prácticamente se inició en el pensamiento político tras la lectura del libro de Mary Wollstonecraft, Vindicación de los derechos de la mujer, al mismo tiempo que leía a Saint-Simon. En los quince años siguientes, asistió a la eclosión que significó el planteo de emancipación de la mujer por parte de los diferentes grupos socialistas, mientras el liberalismo, en todas sus vertientes, rechazaba cualquier tipo de modificación en la situación legal y social de las mujeres.

El planteamiento generalizado de la situación de inferioridad de la mujer comienza con la revolución francesa. Olympe de Gouges y Condorcet en Francia (Gouges, 2007), Mary Wollstonecraft en Inglaterra (Wollstonecraft, 1998), Theodor von Hippel en Alemania (Evans, 1980: 9), marcan el primer momento en que surge la temática de los derechos de la mujer y un replanteo acerca de la "naturaleza" femenina. El significado de esta primera ola de reflexión sobre la situación de la mujer consiste en un planteo general y en cierto modo abstracto de los derechos femeninos, concreta y completamente negados tanto por la sociedad que moría como por la que estaba naciendo. "Los derechos de la mujer", de Olympe de Gouges (2007: 111), denuncia que el varón

3. No están claras las causas de la muerte de Flora Tristán. Desde el comienzo de su periplo, en abril de 1844, Flora se queja en su diario de jaquecas, malestares digestivos y disentería, a lo que se une el sobreesfuerzo y la mala alimentación. Finalmente cae postrada a fines de octubre de ese año y es alojada en casa de una pareja de ex sansimonianos, donde muere el 11 de noviembre. Eléonore Blanc conservó el diario de esta gira, que recién fue publicado en 1973. 
oprime a la mujer, sostiene en forma algo ambigua que ésta debe estar representada en la Asamblea Nacional y reivindica su derecho a "la libertad, la propiedad, la seguridad y, sobre todo, la resistencia a la opresión" (idem: 115).

El marqués de Condorcet, mucho más avanzado que Olympe de Gouges, propone específicamente la concesión de los derechos cívicos a las mujeres (Condorcet, 2007: 201), en un texto donde destruye, con una lógica arrasadora, todos los argumentos y prejuicios que se oponen a ello.

Mary Wollstonecraft, por su parte, del otro lado de la Mancha, recoge las ideas libertarias de la revolución francesa y reivindica sobre todo el derecho de la mujer a la educación, la cual, afirma, demostrará que la supuesta "naturaleza femenina" no es más que el producto del estado de sometimiento, que la reduce al estado de un animal doméstico y un juguete del hombre (Wollstonecraft, 1998: 10 y 40).

Estos textos denuncian la situación de la mujer, pero también hay que tomar en consideración que, en los sucesos revolucionarios, las mujeres tuvieron una participación destacada. Claire Lacombe y Théroigne de Méricourt, por ejemplo, estuvieron en la izquierda jacobina, y la primera dirigió la Sociedad de Mujeres Republicanas Revolucionarias, organización que fue reprimida e ilegalizada por Robespierre.

Pero estas reflexiones, al calor de la revolución en Francia y su contagio al conjunto de Europa, no convirtieron a los liberales en abogados del feminismo ni generaron algún tipo de movimiento más extenso por los derechos de la mujer. Como afirma Pierre Rosanvallon (1992: 136): "A pesar de su ardiente individualismo, los hombres de 1789 no consideran a las mujeres como «verdaderos individuos». Éstas permanecen para ellos encerradas en la esfera de la actividad doméstica, exteriores a la sociedad civil". El liberalismo mostró en este tema su verdadera cara: más que un planteo abstracto y universal sobre la libertad de los individuos, se evidenció como una doctrina para la libertad exclusiva de los propietarios varones blancos. Ningún grupo liberal planteó (hasta muy avanzado el siglo XIX) la igualdad legal entre varones y mujeres, ni el sufragio femenino, y ese honor le correspondió al socialismo.

Fourieristas y sansimonianos no solamente plantearon la necesidad de una "emancipación de la mujer" sino que además ofrecieron algunas soluciones y generaron un movimiento de mujeres del cual surgió, pocos años después, la palabra "feminismo", en francés. El primero de todos es Charles Fourier, quien vinculó la situación de la mujer a la evolución social: "Los progresos sociales y cambios de período se operan en razón del progreso de las mujeres hacia la libertad; y las decadencias de orden social se operan en razón del amenguamiento de libertad de las mujeres. [...] La extensión de los privilegios de las mujeres es el principio general 
de todos los progresos sociales" (Fourier, 1946: 243). Es decir que la opresión de la mujer era (es) el índice que nos permite medir el grado de civilización y de progreso de una sociedad. ${ }^{4}$

Pero más importante que las derivaciones dentro del fourierismo fueron las elaboraciones que se realizaron en el otro grupo protosocialista francés, el de los sansimonianos. Prosper Enfantin, uno de los líderes de este grupo tras la muerte del maestro en 1825, lee a Fourier y, a partir de 1831, reivindica para las mujeres, dentro de su movimiento, un papel similar y al mismo nivel que los varones, abogando a la vez por la "emancipación de la mujer" y por la "rehabilitación de la carne" (Charléty, 1969: 135)..$^{5} \mathrm{El}$ sansimonismo planteó que, a diferencia del catolicismo, encabezado por un "padre", la religión sansimoniana debía estar dirigida por un "padre" y una "madre". A partir de esta reivindicación, el sansimonismo fue el primer grupo político que incorporó mujeres tanto en sus organismos de base como en los niveles de dirección. Entre las más conocidas, podemos nombrar a Claire Bazard, Eugenie Niboyet (una de las que lideraba los grupos proletarios), Euphrasie Rodrigues, Cécile Fournel, Aglaé Saint-Hilaire.

Pero un grupo de mujeres, particularmente, toma estas ideas para darles un curso concreto y empieza a publicar un periódico quincenal, La Femme Libre, que desde el primer número debe cambiar su nombre por L'Apostolat des Femmes, y al año siguiente Tribune des Femmes. Lo dirigen Marie-Reine Guindorf, Suzanne Voilquin y Désirée Veret y aparece entre 1832 y 1834. En su primer número, realizan un "Llamamiento a las mujeres":

Cuando todos los pueblos se agitan en nombre de la $\mathrm{Li}$ bertad, y el proletario reclama su liberación, ¿nosotras, las mujeres, seguiremos pasivas frente a este gran movimiento de emancipación social que se opera frente a nuestros ojos? $¿$ ¿Nuestra suerte es tan feliz, que no tenemos nada que reclamar? La mujer, hasta el presente, ha sido explotada, tiranizada. Esta tiranía, esta explotación, debe cesar. Nacimos libres como el hombre, y la mitad del género humano no puede ser, sin injusticia, sometida al otro. Comprendamos nuestros derechos; comprendamos nuestro poder; tenemos el poder de atracción, el poder del encanto, arma irresistible, sepamos emplearlo. Re-

4. Ya comentamos más arriba el folleto de William Thompson y Anna Wheeler, fourieristas ingleses, sobre la emancipación de la mujer.

5. La "rehabilitación de la carne" implicaba una crítica al rechazo de la carnalidad y la sensualidad por parte de la iglesia católica. 
chacemos por esposo al hombre que no sea lo suficientemente generoso como para aceptar compartir su poder; no queremos más la fórmula: "Mujer, sé sumisa a tu marido». Queremos el matrimonio según la igualdad... ¡Es mejor el celibato que la esclavitud!" (No 1 , pp. 1-2, traducción propia).

Vemos aquí que la liberación de las mujeres es puesta en relación directa con la emancipación de los trabajadores. Incluso ambos procesos no son vistos como contemporáneos sino que el movimiento femenino debiera preceder al movimiento proletario. El no 3 está encabezado por un lema que lo aclara: "Con la liberación de la mujer vendrá la liberación del trabajador". ${ }^{6}$

Este grupo de sansimonianas siguió activando, en la medida de sus posibilidades, por la emancipación femenina, aunque su periódico no duró más de dos años. Superaron en muchos aspectos a las teorías nacidas con la revolución francesa: la mujer ya no sólo tenía derechos abstractos y universales sino que además debía superar los innumerables aspectos en los cuales era legal y realmente inferior al hombre. Las ideas en torno a la igualdad de género no se planteaban como una idea lanzada en el seno de una elite ilustrada sino que se buscaba generar un movimiento de las propias mujeres en lucha por cada uno de los aspectos donde no era satisfecha esa igualdad. En el mismo primer número se lo plantea claramente: "Nuestro objetivo es la asociación. Como las mujeres no han tenido hasta ahora ninguna organización que les permita entregarse a algo grande, no han podido ocuparse más que de pequeñeces individuales que las han confinado al aislamiento" (n ${ }^{\circ}$ 1: 6-7, traducción propia).

Por otra parte, el problema de la mujer es planteado ahora como un problema politico, y no individual. Quieren para las mujeres el lugar que les corresponde "en el templo, en el Estado y en la familia" $\left(\mathrm{n}^{\circ} 1\right.$ : 6), consigna que será enunciada repetidas veces en esta publicación. No es un problema de la redacción de la constitución, como en Olympe de Gouges o, en última instancia, también en Condorcet, ni como un problema educativo, como en Wollstonecraft. El sometimiento de la mujer con respecto al varón es un problema que concierne al conjunto de la sociedad, y se denuncia al Estado y a los poderes que se cobijan

6. Esta consigna, a nuestro entender, no debe ser considerada con un matiz actual "conservador" (no luchar por la liberación de los trabajadores si no se consigue antes la liberación de las mujeres) sino en un sentido potenciador: la liberación de los obreros está dificultada por el tradicionalismo femenino, combatir este último es ayudar en la emancipación general del pueblo. 
en éste como los sostenedores de esa situación. Desde este punto de vista, la emancipación de la mujer es presentada como un objetivo por el cual luchar y que está vinculado estrechamente a otras situaciones de otros grupos sociales que también sufren privaciones, discriminación o explotación. No podemos dejar de anticipar aquí que en 1848 las primeras feministas estadounidenses, en Seneca Falls, unieron la problemática de la mujer al problema de la discriminación racial y la esclavitud (Evans, 1980: 49).

La revolución de 1848 encontrará a casi todas las feministas sansimonianas en la primera línea de batalla por las reivindicaciones de la mujer. Désirée Veret propone una ley de divorcio y participa en la dirección de los talleres nacionales. Pauline Roland es elegida para dirigir la Unión de Maestros y Maestras, por lo cual es encarcelada en 1850 por Luis Bonaparte, y muere al año siguiente por el maltrato sufrido en prisión. Eugenie Niboyet y Jeanne Deroin fundan La Voix des Femmes en 1848, y Deroin y Véret sacan a luz un diario, La Politique des Femmes (después de dos números, obligadas a cambiar el título por L'Opinion des Femmes). Jeanne Deroin, además, denuncia el "sufragio universal" instaurado por la revolución como un "sufragio universal masculino", siendo la primera que utiliza esa expresión, y en 1849 se presenta como candidata a diputada, a pesar de que las mujeres no tienen permitido ser electoras ni elegibles. Sufre el rechazo no solamente de los poderes y del partido del orden sino también de algunos de sus compañeros de militancia, entre ellos George Sand, temerosos de "hacer el ridículo" frente a la sociedad.

Pero nos hemos adelantado, hablando de la revolución de 1848, que Flora Tristán no conoció. Desde fines de los años 30, Flora se constituye como continuadora de estos planteos: fue amiga de Pauline Roland, a través de la cual conoció a Jeanne Deroin, y tuvo contacto directo con George Sand y con Hortense Allart. Pero sus planteos fueron más allá que el de las iniciadoras sansimonianas.

Discute en primer lugar las teorias discriminatorias sobre la mujer en Aristóteles, en la Biblia cristiana, en el islamismo y en el hinduismo (Tristán, 1993: 110-111). La iglesia, afirma, identificó a la mujer con el pecado, el legislador la sacó de la legislación, el filósofo la tildó de irracional (idem: 114). "Por lo tanto, se la ha educado para ser una graciosa muñeca y una esclava destinada a distraer a su dueño y a servirle" (idem: 115). Frente a este pensamiento retrógrado, Flora reivindica el gran paso adelante que significó el socialismo para llegar a un planteo de emancipación de las mujeres, retomando las ideas de Enfantin y de Fourier para darles una perspectiva más amplia.

El obrerismo de Flora no la enceguece en cuanto a la situación de la mujer en la clase trabajadora. La miseria genera las peores discordias 
en el hogar, empeora aún más la dependencia de la mujer con respecto al marido y generalmente hace de ellas esclavas domésticas. En ese sentido, las mujeres son "la clase más oprimida" (idem: 103), ya que a la vez que es explotada como trabajadora, es oprimida por el sexo masculino. Esta doble explotación que sufren las mujeres no determina que se las pueda identificar como una clase social aparte: su lucha, aunque sea por el reconocimiento de derechos individuales (y, en ese sentido, una lucha democrática), sólo tiene sentido en el marco de la lucha por la liberación de todos los trabajadores. Sostuvo que "la emancipación de los obreros es imposible en tanto que las mujeres permanezcan en este estado de embrutecimiento" (idem: 130), retomando la idea que ya habian esbozado en L'Apostolat des Femmes: la liberación de las mujeres es concebida como una condición de la emancipación obrera. Y no idealiza a las mujeres a las que convoca con su mensaje:

Estas pobres criaturas [...] se enfurecian con el marido y conmigo porque el obrero perdía algunas horas de su tiempo ocupándose de ideas políticas y sociales. [...] Estas mismas mujeres me detestan, hablan horrores de mí y, sin el miedo a la cárcel, serían capaces de llevar su celo hasta el punto de venir a injuriarme a mi casa y pegarme, y todo esto porque yo cometo el gran crimen, dicen, de meter en la cabeza de sus hombres ideas que les obligan a leer, a escribir, a hablar entre ellos, todas ellas cosas inútiles que hacen perder tiempo. (Tristán, 1993: 130-131)

Por eso incluyó en su libro La unión obrera un capítulo especial dedicado a las mujeres y, en todo momento, sus propuestas iban dirigidas a los dos géneros. En ese sentido, debemos señalar que es la antecesora de un tipo de enunciación, hoy mucho más extendido, que se preocupa por recordar constantemente la interpelación a los dos géneros ("todos y todas", "los obreros y las obreras", etc.), expresión frecuente tanto en sus publicaciones como en el diario de su gira por Francia.

Esta primera época de feminismo socialista no fue pródiga en la elaboración de consignas específicas para el género femenino, pero por su situación personal Flora Tristán fue una firme defensora del derecho al divorcio, tema al que le dedicó un folleto, famoso en su momento. El problema del sufragio quedaba relegado, en su generación y también en Flora, a una reforma política que podría abarcar tanto a varones como a mujeres. Pero la mayoría de los socialistas de la época eran renuentes a involucrarse en la lucha por el sufragio universal (incluso masculino) o en la defensa de derechos individuales o de minorías. Se estaba tratando de denunciar la espantosa miseria en la que estaba sumida el 
proletariado y todo tipo de reivindicación democrática era sentida como superflua y burguesa. En ese marco, los derechos de las mujeres eran doblemente silenciados: en parte porque no se comprendia su lucha democrática, en parte porque esa lucha democrática para el mismo género masculino era vista como improcedente. Debieron pasar varios decenios hasta que las feministas socialistas de comienzos del siglo XX procuraron arrebatarle a las sufragistas "burguesas" el estandarte de las reivindicaciones específicas.

\section{Balance}

En Flora Tristán se agitan las aguas que van formando la corriente poderosa del socialismo, que tomará una forma sustancial con la Asociación Internacional de Trabajadores. Al igual que sucede con todos los pensadores anteriores a Marx, podemos ver en ella elementos contradictorios, inconclusos, abstractos, en referencia a la gran sintesis que realizó el pensador alemán. Cuando nos acercamos a analizar esta época, nos vemos impelidos a realizar constantes contextualizaciones, de manera de reponer a ojos de los lectores el verdadero cuadro de situación que presenta la época. De otra forma, las ideas son entendidas en marcos teóricos ajenos y extemporáneos y se les puede otorgar una coherencia que en su momento no tuvieron. Esta prevención nos lleva a realizar algunas puntualizaciones.

Como ya se ha dicho, Flora Tristán no era una socialista revolucionaria. Buscó afanosamente que la clase obrera se constituya en un marco pacífico y alejada de las asonadas y los alzamientos. Esta idea, que animaba a la mayoría de las corrientes del socialismo originario, provenía de una experiencia negativa de la clase obrera francesa: en todas las revoluciones los obreros fueron su principal fuerza y su primera víctima, pero jamás habían podido gozar de sus beneficios. Sin embargo, la idea de que los trabajadores deben constituirse como una clase separada del resto de las clases sociales, para poder elaborar su programa propio y con instituciones diferenciadas, en función de una emancipación general de la sociedad, resulta, en su momento, mucho más revolucionario que los intentos insurreccionales dirigidos por una minoria, en desconocimiento total del verdadero proletariado.

Este pacifismo también lo podemos vincular a su admiración por las luchas del pueblo irlandés, en la figura del miembro del Parlamento inglés Daniel O'Connell. Por un lado, Flora Tristán tuvo la perspicacia política (que otros miembros de su generación no tuvieron) de apoyar la lucha de los irlandeses por su liberación, lo cual nos presenta otra faceta de su internacionalismo. Por el otro, no se puede dejar de observar que apoyaba a un representante del reformismo y del gradualismo 
independentista, que mantuvo cierta coexistencia amistosa con el poder imperial de Londres.

Flora enmarcaba su prédica en un cristianismo elemental, y su militancia la entendía en términos de apostolado y sacrificio. El ateísmo que prevaleció en el socialismo desde Marx y Bakunin no debe impedirnos observar que todas las corrientes iniciales del socialismo eran cristianas, en alguno u otro sentido, aunque rechazando de plano a las iglesias constituidas (Díaz, 2003). Para Saint-Simon, su doctrina no era más que la aplicación de los preceptos del cristianismo a la política. Fourier desarrolla la "demostración" de la necesidad de una utopía de abundancia (que llama "Armonia") en la misma bondad de Dios. Las invocaciones a Dios y, sobre todo, a Jesús (que se convierte en una nueva bandera de lucha en los años 40, retomada más adelante por los anarquistas), son frecuentes en Robert Owen, Louis Blanc, Etienne Cabet y PierreJoseph Proudhon, sólo por nombrar los más significativos. Flora Tristán no escapaba a esta tendencia. Incluso podríamos agregar que sólo esa concepción de apostolado, donde la persona se sentía llamada a una tarea que superaba las fuerzas del hombre común y donde las adversidades (la falta de medios, las críticas, las burlas, las persecuciones) eran soportadas bajo la forma de un martirologio similar al que debió tolerar Jesús, le permitía a los primeros socialistas difundir su palabra sin caer en la resignación. Fue la "forma" religiosa lo que le permitió a los sansimonianos extenderse por toda Francia, Bélgica, Italia y el occidente de Alemania. La difusión del owenismo en Inglaterra sólo fue posible con el envio de "misioneros" a todas las ciudades de la isla.

Otro aspecto importante a señalar es que las ideas de Flora Tristán no son en absoluto "utópicas", ni creemos que haya que catalogarlas, más por comodidad que por caracterización, dentro del "socialismo utópico". Si definimos el utopismo como una teoria que, ante determinados objetivos generales y complejos, plantea soluciones demasiado simples y, por ello mismo, abstractas e infantiles, Flora evidentemente no cabe dentro de ese esquema. Más que plantearse alguna elucubración de máxima envergadura sobre la emancipación de los trabajadores y de las mujeres, centró su accionar (que ella llamó apostolado y nosotros podemos denominar "militancia") en la constitución del proletariado como clase y su organización a partir de pequeños grupos que abogaran por una unidad firme y cerrada de la totalidad del proletariado, para ir preparando su liberación. Si consideró que su objetivo podía ser rápidamente consumado no fue por "utopismo" sino por ver, del otro lado de la Mancha, que la clase obrera inglesa ya había podido constituirse de esa manera, a través de una serie de luchas teóricas y prácticas, contra la burguesía y su Estado.

La década de 1840 fue un momento muy particular de la historia 
de Europa. Las grandes teorias socialistas, de Saint-Simon, Fourier, Owen, ya se habían estrellado contra el muro de la realidad y sus restos, dispersos, conformaban una miríada de grupos que intentaban encontrar un sendero para que el proletariado saliera de la miseria y la ignorancia. Con la gran burguesía liberal en el poder, habia surgido un activo movimiento republicano y democrático, que abogaba por el sufragio universal y la democracia representativa, generalmente con el método de la asonada y el motín armado. Otro sector socialista actuaba en consonancia con este último grupo republicano: los blanquistas, los herederos de Babeuf y los incipientes grupos "comunistas". Conspirativos, revolucionarios y radicales en sus planteos metodológicos, carecian sin embargo de profundidad teórica y tuvieron poco contacto con el proletariado de carne y hueso.

La gran concepción del socialismo moderno estaba naciendo en ese misma década, retomando las mejores tradiciones de los movimientos anteriores. Cada pensador, cada grupo, aportaba su visión unilateral de los fenómenos, para confluir en una corriente común que esperaba a sus ideólogos y a sus organizaciones específicas. Recorrer las huellas dejadas por esos antecesores es la mejor manera de comprender cuánto de novedad y de continuidad hay en la obra de Marx y Engels. A Flora Tristán le cabe un lugar significativo en ese periplo.

\section{Bibliografia}

Armand, F. y R. Maublanc (1996), Fourier, México: Fondo de Cultura Económica.

Bebel, Augusto (1941), La mujer y el socialismo, Buenos Aires: Problemas. Charléty, Sébastien (1969), Historia del sansimonismo, Madrid: Alianza.

Claudín, Fernando (1985), Marx, Engels y la Revolución de 1848, Madrid: Siglo Veintiuno.

Cole, G.D.H. (1980), Historia del pensamiento socialista, México: Fondo de Cultura Económica.

Condorcet (2007), "Sobre la admisión de las mujeres al derecho de ciudadanía", en Olympe de Gouges, ob. cit.

Démier, Francis (2004), "Les saint-simoniens à la rencontre des ouvriers parisiens au tournant des années 1830", en Pierre Musso (dir.), L'actualité du saint-simonisme. Colloque de Cerisy, París: PUF.

Díaz, Hernán (2003), "Saint-Simon, del liberalismo al socialismo", Razón y Revolución, 11.

Dolléans, Édouard (1960), Historia del movimiento obrero, tomo 1, Buenos Aires: Eudeba.

Evans, Richard J. (1980), Las feministas. Los movimientos de emancipación de la mujer en Europa, América y Australasia, 1840-1920, Madrid: Siglo Veintiuno. 
Fourier, Charles (1946), El falansterio, Buenos Aires: Intermundo.

Fraisse, Geneviève (1998), "Féminisme", en AA.VV., Les notions philosophiques, París: PUF, vol 1.

Gamba, Susana (2009), Diccionario de estudios de género y feminismos, Buenos Aires: Biblos.

Gouges, Olympe de, et al. (2007), Cuatro mujeres en la Revolución Francesa, Buenos Aires: Biblos.

Jardin, André (1998), Historia del liberalismo politico, México: Fondo de Cultura Económica.

Kupchik, Christian (1999), "Flora Tristán", en El camino de las damas, Buenos Aires: Planeta.

Marco, Yolanda (1993), Feminismo y utopia, México: Fontamara.

Marx, Karl y Friedrich Engels (1959), La sagrada familia y otros escritos [1845], México: Grijalbo.

- (1979), Imperio y colonia. Escritos sobre Irlanda, México: Cuadernos de Pasado y Presente.

Marx, Karl y Arnold Ruge (1970), Los Anales Franco-Alemanes, Barcelona: Martínez Roca.

Mayer, Gustav (1979), Friedrich Engels. Biografia, México: Fondo de Cultura Económica.

McMillan, James F. (2011), The Development of Women's Movements, 1789-1914, University of Strathclyde, http:/ /www.keele.ac.uk/history/ currentgraduates.

Mehring, Franz (1967), Carlos Marx. Historia de su vida, Barcelona: Grijalbo.

Picon, Antoine (2002), Les saint-simoniens, París: Belin.

Rancière, Jacques (2010), La noche de los proletarios, Buenos Aires: Tinta Limón.

Rosanvallon, Pierre (1992), Le sacre du citoyen, París, Gallimard.

Saint-Simon, Claude Henri conde de (2004), Nuevo cristianismo [1825], Buenos Aires: Biblos.

Sazbón, José (2007), "Figuras y aspectos del feminismo ilustrado", en Olympe de Gouges (2007), ob. cit.

Stuart Mill, John y Harriet Taylor Mill (1973), Ensayos sobre la igualdad sexual, Barcelona: Península.

Tristán, Flora (1946), Peregrinaciones de una paria [1838], Lima: Cultura Antártica.

- (1972), Paseos en Londres [1840], Lima: Biblioteca Nacional del Perú.

- (1993), La Unión Obrera [1843], en Yolanda Marco, Feminismo y utopía, ob. cit.

- (1973), Le tour de France [1844, edición póstuma], París: Tête de Feuille, notas de Jules Puech.

Vidal, Malena y Adela Reck (2006), “Flora Tristán”, en Andrea D’Atri (ed.), Luchadoras. Historias de mujeres que hicieron historia, Buenos Aires: IPS. 
Wollstonecraft, Mary (1998), Vindicación de los derechos de la mujer [1792], Buenos Aires: Perfil.

$$
* * *
$$

Resumen: El artículo analiza el papel cumplido por Flora Tristán en la elaboración de conceptos centrales del socialismo, como son la lucha para que la clase obrera se constituya como clase organizada y consciente de su rol en la política francesa, y la necesidad de un avance en la liberación de las mujeres, como parte de la lucha política por la emancipación general de la sociedad. Para ello se analiza, por un lado, la propia obra escrita de Flora Tristán y, por el otro, se vincula su pensamiento con la trama abierta por las corrientes socialistas y feministas de Francia y de Inglaterra, desde la Restauración de 1815 hasta las vísperas de la revolución de 1848.

Palabras clave: Flora Tristán - feminismo - socialismo premarxista - Francia - siglo XIX

\begin{abstract}
The article analyzes the role played by Flora Tristan in the development of central concepts of socialism, such as the fight to constitute the working class as an organized and conscious force in French politics, and the need to promote a step forward in women's liberation as part of the political struggle for general emancipation of society. We examine, on the one hand, Flora Tristan works, and, on the other, the links between her thought and socialist and feminist currents in France and England, from the Restoration of 1815 until the eve of the 1848 revolution.
\end{abstract}

Keywords: Flora Tristán - feminism - premarxist socialism - France - Nineteenth century

Recepción: 21 de junio de 2012 - Aprobación: 3 de agosto de 2012 